\title{
Self Care of Heart Failure and Health Related Quality of Life among Congestive Heart Failure Patients in Punjab, India
}

\author{
Anurag Bhai Patidar*, Harpreet Kaur**, Rajesh Kumar*** \\ *Associate Professor, Nursing College, All India Institute of Medical Sciences, Bhopal. Ex-Lecturer, DMCH \\ Nursing College, Ludhiana, Punjab. \\ ** Ex-M.Sc. Nursing Scholar, College of Nursing, Dayanand Medical College and Hospital, Ludhiana. \\ $* * *$ Nursing Tutor, College of Nursing Safidon, Jind, Haryana-126112
}

Corresponding Author: Anurag Bhai Patidar

\begin{abstract}
Introduction and Background: Congestive heart failure is the inability of heart to pump sufficient blood to meet the needs of tissues for oxygen and nutrients. Appropriate self-care is associated with prevention or early detection of health problem and better overall health related quality of life in patients with chronic illness such as heart failure.
\end{abstract}

Aims and Objectives: To assess and ascertain correlation between self care of heart failure and health related quality of life among congestive heart failure patients.

Materials and Methods: A correlational study was conducted to assess and ascertain the correlation between self-care of heart failure and health related quality of life among congestive heart failure patients. Data was collected from 100 heart failure patients seeking treatment at Outpatient Department of Cardiology in Hero DMC Heart Institute, Ludhiana. Convenience sampling technique was used to recruit subjects. "Self care of heart failure index" was used to assess self care of heart failure and "Minnesota living with heart failure questionnaire" was used to assess the health related quality of life. Data was collected by structured interview method and analysed by using descriptive and inferential statistics.

Results: Maximum of the heart failure patients (84\%) had good self-care confidence, more than half (52\%) had good self care management and one third (33\%) patients had average self care maintenance. Half of the subjects had excellent quality of life, followed by $34 \%$ had good quality of life. Weak positive correlation was found between self care of heart failure and health related quality of life. There was no statistically significant association found between selected socio-demographic variables and self-care of heart failure.

Conclusion: There was good self-care confidence, management and average self care maintenance but overall patients had excellent health related quality of life.

Key words: - Self-care, Health related quality of life, Congestive heart failure.

\section{INTRODUCTION AND BACKGROUND}

Heart failure is a world-wide health problem that is associated with burdening health care cost, significant morbidity and mortality. In western countries, where heart failure is predominantly a disease of the elderly, in India it also affects younger age group. Moreover, incidence of HF has not declined during the past two decades and patients with HF have to adjust with too many life-altering behaviours and are often readmitted with acute care due to lack of knowledge about self-care.

Numerous treatment option are available for heart failure that includes 
medication, implantable cardioverter, cardiac resynchronization therapy, internal cardiac monitoring devices, left ventricular assist devices and cardiac transplantation ${ }^{1}$. In addition to all of these modalities as mentioned, patient can personally impact the health by self care management.

Self care referred to the decision making that underlies the choice of positive health practices (also called 'self-care maintenance') and the behaviours used to manage signs and symptoms of illness and disease (termed 'self-care management') or self care is the process in which individual or care giver performs the activities such as treatment adherence, follow low cholesterol, low fat, and no-added-salt diet with a fluid restriction, exercise, stress management and energy conservation.

Important aspects of self-care are limiting sodium and fluid intake, exercise, stress management and energy conservation aerobic exercise which increases heart rate and makes circulation better ${ }^{2}$.

There is increasing evidence that self-management programme for $\mathrm{CHF}$ patients have positive effects on quality of life $^{3}$. Evaluating the quality of life has been shown to be useful in arriving at a prognosis in terms of mortality and hospitalization. F Shojaei et al revealed that $26 \%$ of patients had good self-care behaviour and the behaviour of "I take my medication as prescribed was the most performed behaviours ${ }^{4}$.

Patient with heart failure experience various physical and emotional symptoms such as dyspnea, fatigue, sleeping difficulties, depression and chest pain. These symptoms limit patient's daily physical and social activities and result in poor quality of life $\mathrm{s}^{5}$. Moreover, poor quality of life is related to high hospitalization and mortality rates ${ }^{6}$.

It has been reported that patients with HF who demonstrate decreased selfcare ability in various activities such as medication compliance, following a lowsodium diet, maintaining fluid restrictions, weighing themselves daily, and identifying the early warning symptoms of worsening heart failure have frequent hospitalizations and decreased quality of life. Jaarsma Tinny et al revealed that education enhanced selfcare behaviour significantly at 3 and 9 month after discharge ${ }^{7}$.

In India, researchers experienced that most of the congestive heart failure patients may have difficulty to follow a lowsodium diet because they are unfamiliar with reading food labels. So, self-care has emerged as a mean of empowering patients to have more control over their daily lives through active participation in their management. Connell A et al revealed that patients with low socio-economic status had lower self-care behavior and indigent heart failure patients face unique challenges that contribute to poor self care ${ }^{8}$.

Seto et al revealed that better quality of life was associated with higher self care confidence and barrier to self care caused anxiety to the patients. The self care barriers included lack of self care education, financial constraints, lack of perceived benefit, low self efficacy ${ }^{9}$. Similarly, Dunn $\mathrm{KS}$ et al also reported significant association between self care confidence and quality of life ${ }^{10}$.

There are few studies which reported self-care behaviour among congestive heart failure patients globally and in India there is paucity of work in this direction. Therefore, the present study was planned to assess and determine the relationship between self-care of heart failure and health related quality of life among congestive heart failure patients.

\section{MATERIAL AND METHODS}

This descriptive co-relational study was conducted at outpatient department of cardiology in Hero DMC Heart Institute (HDHI), Ludhiana. HDHI, is tertiary care cardiac centre providing facilities for cardiac patients medical surgical and nursing care. The population under study was all the stable congestive heart failure patients, seeking treatment at Outpatient Department of Cardiology in HDHI, Ludhiana. 
A total 100 stable patients suffering with congestive heart failure seeking treatment at Outpatient Department of Cardiology in HDHI, Ludhiana, were selected for study. Study sample was drawn by using convenience sampling technique. Those patients who were diagnosed with congestive heart failure and whose clinical condition was stable over the past four weeks as evidenced by no change in medications were included in the study. Those patients who were not willing to participate were excluded from study.

The study was approved by Research \& Ethics Committee, Dayanand Medical College and Hospital, Ludhiana and Baba Farid University of Health and Sciences, Faridkot. An informed written consent was taken from each subject. Anonymity of subject and confidentiality of information was assured. It was ensured that study did not affect the participants in any way.

Data was collected using the sociodemographic sheet, clinical profile sheet, self-care of heart failure index (22-item questionnaire sectioned in to 3 subscales: self care maintenance, self care management, and self care confidence). High score on the questionnaire is indicative of better self-care abilities and is based on 4 point Likert scale and Minnesota living with heart failure questionnaire (6 point Likert scale to determine how much each of the 21 items had prevented the heart failure patient from living how they would have liked to in the past month). Lower score indicative of better health related quality of life and high score indicative of poor health related quality of life.

Tools were translated in to Punjabi language. Permission for translation of tools in to Punjabi was taken from author and again back translated in to English language with help of experts for validation purpose.

The reliability of tool "Self care heart failure index" and "Minnesota living with heart failure questionnaire" was tested by test-retest method. The reliability of both tools was found to be same $(\mathrm{r}=0.9)$.
Similarly, the reliability of structured sociodemographic sheet and clinical profile sheet was found to be 0.95 and 0.92 respectively.

Data about socio-demographic variables, self care of heart failure and health related quality of life was collected by face to face interview and clinical records were used to fill the clinical profile sheet.

\section{RESULTS}

As depicted in table 1majority of $63 \%$ subjects belonged to age group 51- 70 years, more than half $55(55 \%)$ of subjects were female and $71 \%$ subjects were housewife/non working. $53 \%$ subjects belonged to nuclear family, more than half $52 \%$ subjects were having family members between 5-10 and majority 69\% of the subjects were having monthly family income between (in rupees) 20, 001$40,000 /-$. More than half $(54 \%)$ of the subjects were Sikh followed by $43 \%$ Hindu. Only $32 \%$ of the subjects were educated up to elementary level and $24 \%$ were illiterate. Majority (64\%) of the subjects were living in urban area and were vegetarian (76\%). More than half $(59 \%)$ of the subjects were having sedentary life style.

Table1: Sociodemographic Characteristics of congestive heart failure patients, $\mathrm{N}=\mathbf{1 0 0}$

\begin{tabular}{|c|c|}
\hline Sociodemographic Characteristics & $(\%)$ \\
\hline \multicolumn{2}{|l|}{ Age (in years)* } \\
\hline$\leq 30$ & 04 \\
\hline $31-50$ & 20 \\
\hline $51-70$ & 63 \\
\hline$\geq 70$ & 13 \\
\hline \multicolumn{2}{|l|}{ Gender } \\
\hline Male & 45 \\
\hline Female & 55 \\
\hline \multicolumn{2}{|l|}{ Occupation } \\
\hline Farmer & 05 \\
\hline Self employed & 20 \\
\hline Labourer & 04 \\
\hline Housewife/ non-working & 71 \\
\hline \multicolumn{2}{|l|}{ Total number of family members } \\
\hline$<5$ & 41 \\
\hline $5-10$ & 52 \\
\hline$>10$ & 07 \\
\hline \multicolumn{2}{|l|}{ Type of family } \\
\hline Nuclear & 53 \\
\hline Joint & 42 \\
\hline Extended & 05 \\
\hline \multicolumn{2}{|l|}{ Total monthly income (INR) } \\
\hline$\leq 20000$ & 69 \\
\hline $20001-40000$ & 21 \\
\hline$\geq 40001$ & 09 \\
\hline
\end{tabular}


Table 2: Clinical Profile of congestive heart failure patients. $\mathbf{N}=\mathbf{1 0 0}$

\begin{tabular}{|c|c|}
\hline Clinical Variables & $\%$ \\
\hline \multicolumn{2}{|c|}{ Duration of illness (in years) } \\
\hline$<5$ & 83 \\
\hline $5-10$ & 12 \\
\hline$>10$ & 05 \\
\hline \multicolumn{2}{|c|}{ Duration of treatment (in years) } \\
\hline$<5$ & 86 \\
\hline $5-10$ & 10 \\
\hline$>10$ & 04 \\
\hline \multicolumn{2}{|l|}{ Other chronic illness } \\
\hline Diabetes mellitus & 38 \\
\hline Hypertension & 03 \\
\hline Aplastic anemia & 01 \\
\hline Hypothyroidism & 02 \\
\hline Pulmonary Koch & 01 \\
\hline Chronic kidney disease & 02 \\
\hline \multicolumn{2}{|l|}{ Habit of smoking } \\
\hline No & 97 \\
\hline Yes & 03 \\
\hline \multicolumn{2}{|c|}{ Habit of drinking alcohol } \\
\hline No & 97 \\
\hline Yes & 03 \\
\hline \multicolumn{2}{|l|}{ Ejection fraction (in \%) } \\
\hline$\leq 50$ & 89 \\
\hline$\geq 50$ & 11 \\
\hline
\end{tabular}

*Duration of illness: Mean score (3.92 \pm 3.34$)$, Duration of

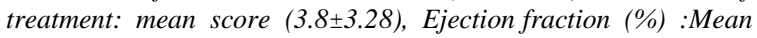
score(33.5 \pm 10.4$)$

Table 2 depicts that maximum $(83 \%)$ of subjects had duration of illness $<5$ years. Mean duration of illness and treatment of study subjects were 3.92 and 3.80 (in years) respectively. $38 \%$ of the subjects had diabetes mellitus and only $3 \%$ of the subjects had hypertension. Maximum $(97 \%)$ of the subjects were non-smoker and maximum $89(89 \%)$ subjects had ejection fraction $\leq 50 \%$. Mean ejection fraction among study subjects was 33.5 \pm 10.4 . Maximum (46\%) of the subjects had dilated cardiomyopathy followed by $(16 \%)$ had Coronary artery disease. One third 31 (31\%) of the subjects were falling in NYHA classII of congestive heart failure and $16 \%$ subjects had NYHA class IV of congestive heart failure.

Table 3 illustrates that majority $(77 \%)$ of the subjects were doing average self care of heart failure whereas only about one fourth $(23 \%)$ of the subjects were doing good self care of heart failure.

The study revealed that majority $(67 \%)$ of the subjects had poor self care maintenance and remaining (33\%) had average self care maintenance. Slightly more than half $(52 \%)$ of the subject were doing good self care management, and $46 \%$ were doing average self care management. Maximum (84\%) of the subjects had good self care confidence.

Table 3: Self care of heart failure among congestive heart failure patients (as per domains), $\mathrm{N}=\mathbf{1 0 0}$

\begin{tabular}{|l|c|l|}
\hline Self care related variables & $\%$ & Criterion measure \\
\hline Self care (overall) & 00 & $00-28$ \\
\hline Poor & 77 & $29-58$ \\
\hline Average & 23 & $59-88$ \\
\hline Good & 67 & $10-20$ \\
\hline Self care maintenance & 33 & $21-30$ \\
\hline Poor & 00 & $31-40$ \\
\hline Average & 02 & $00-08$ \\
\hline Good & 46 & $09-16$ \\
\hline Self care management & 52 & $17-24$ \\
\hline Poor & 00 & $00-08$ \\
\hline Average & 16 & $09-16$ \\
\hline Good & 84 & $17-24$ \\
\hline Self care confidence & \multicolumn{1}{|l}{} \\
\hline Poor &
\end{tabular}

As depicted in figure 1 half of the subjects had excellent quality of life, followed by $34 \%$ had good quality of life and only few (1\%) had poor quality of life. It may due to underrepresentation of class IV patients in our study.

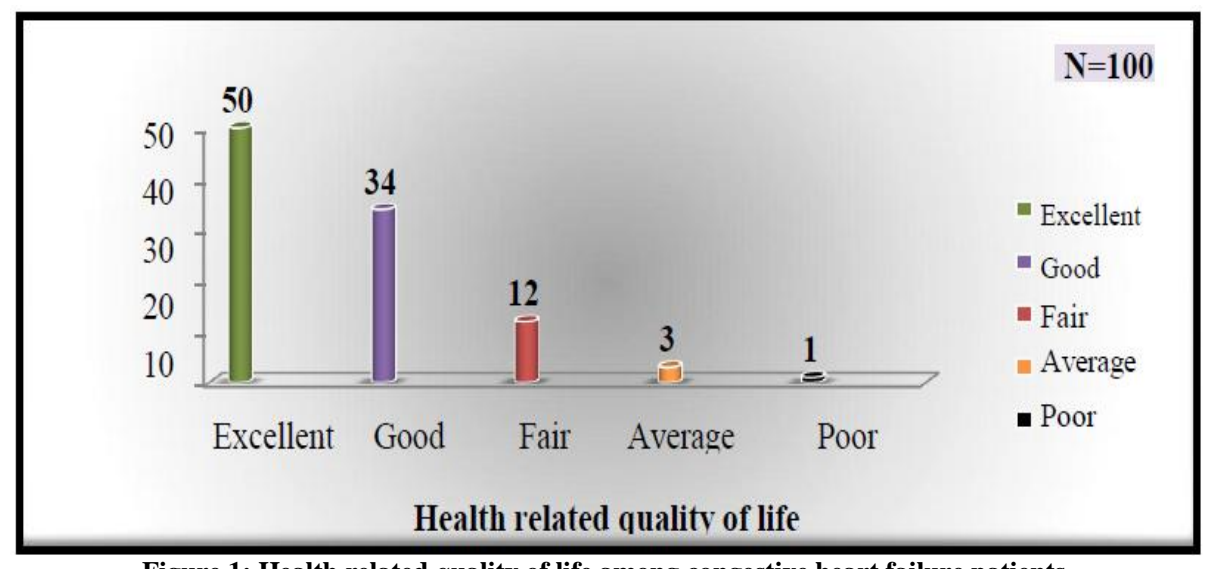

Figure 1: Health related quality of life among congestive heart failure patients. 
The study data revealed that there was weak positive non-significant correlation between self care of heart failure and health related quality.

There was no statistically significant association between self care of heart failure and selected socio-demographic variables (age, gender, marital status and educational level) at 0.05 level of significance. Also, there was no statistically significant association between self care of heart failure and selected clinical variables (NYHA class, duration of present illness and duration of treatment) at 0.05 level of significance.

\section{DISCUSSION}

The present study explored that majority $(67 \%)$ of subjects were doing poor self care maintenance however; slightly more than half $(52 \%)$ of the subjects were doing good self care management and maximum $(84 \%)$ of the subjects had good self care confidence. Result of the present study is supported by previous studies. Tung $\mathrm{HH}$ et al also revealed that there was low level of self care maintenance and management among congestive heart failure patients although self care confidence was $\operatorname{good}^{11}$. Seto et al also reported the similar findings 9 .

The present study revealed that most of patients did not do exercise and morning walk on a regular basis because of physician advice and winter season. Most (70\%) of patients were not weighing themselves on a regular basis as they did not find it useful. However, most of the patients were taking medications and low salt diet. Our findings are supported by F Shojaei et al as they revealed that $26 \%$ of patients had good selfcare behavior and the behavior of "I take my medication" as prescribed was the most performed behaviors ${ }^{4}$.

The present study explored that half of the subjects were had excellent quality of life followed by $34 \%$ good quality of life, $12 \%$ fair quality of life, $3 \%$ average quality of life and only one $1 \%$ had poor quality of life. These findings are supported by a previous researches conducted by S. Heo et al on heart failure patients in Indiana. Results of this study revealed that patients perceived that heart failure had serious impact on quality of life, but most evaluated their quality of life as good nonetheless ${ }^{12}$.

There was weak non-significant $(\mathrm{P}>0.05)$ positive co-relation between self care of heart failure and health related quality of life among congestive heart failure patients. Similar findings were reported by HG Buck et al on ${ }^{13}$.

In contrast to the results of the present study Dunn KS reported that self care confidence was significantly associated with quality of life at $(\mathrm{p}<0.05)^{10}$. But in the present study findings were opposite it may be due to small sample size of research study.

Age, gender, marital status, education status, NYHA class of congestive heart failure, duration of illness, duration of treatment were not significantly associated with self care of heart failure ( $p>0.05)$. These findings are supported by a previous study which revealed that patients had low level of self care behavior of heart failure but only knowledge of heart failure and social support were significantly associated with self-care behavior ${ }^{14}$.

\section{CONCLUSION}

The findings of present study revealed that there was good self care confidence, management and average self care maintenance among congestive heart failure patients but overall patients had excellent quality of life. Therefore, weak positive co- relation found between self care and health related quality of life ( $p>0.05)$. No statistically significant association was found between age, gender, education status, marital status, NYHA class of patient, duration of present illness, duration of treatment and self care.

\section{Recommendations}

Similar study can be conducted on a large size sample to generalize findings. Also, interventional studies can be planned to assess the efficacy of various self care 
activities on health related quality of life of heart failure patients.

\section{Implications}

Continuing education should be provided to the nursing personnel and they should be sensitized regarding importance of self care in heart failure so that health related quality of life of CHF patients can be improved. Patients self care abilities should be evaluated before discharge from hospital and efforts should be made to improve their abilities through nurse led clinics.

\section{Acknowledgement: None}

\section{Conflict of Interest: None}

Source of Funding: None

Ethical Approval: Approved

\section{REFERENCES}

1. Machaj F, Dembowska E, Rosik J, Szostak B, Mazurek-Mochol M, Pawlik A. New therapies for the treatment of heart failure: a summary of recent accomplishments. Ther Clin Risk Manag. 2019;15:147-155.

2. MK Debra, F John Watkins. Conceptualizing self-care in heart failure. Life course model of patient characteristics. 2008; 23(3): 205-18.

3. Smeulders Esther, CM van Haastregt Jolanda, FM van Hoef Elisabeth, TM van Eijk Jacques and IJM Kempen Gertrudis. Evaluation of a selfmanagement programme for congestive heart failure patients. MC Health Survey Research 2006; (6): 91.

4. F Shojaei, SM Ebrahimi, S Assemi. Self-care in heart failure patients. Heart and lung 2011; 1034-38.

5. Patidar AB, Andrews GR, Seth S. Prevalence of obstructive sleep apnea, associated risk factors, and quality of life among Indian congestive heart failure patients: a cross-sectional survey.
J Cardiovasc Nurs. 2011 Nov-Dec; 26(6):452-9.

6. H Seongkum ,MK Debra, O Chizimuzo, AL Terry. Quality of life in patients with heart failure: Heart Lung. 2009; 38(2): 100-108.

7. J Tinny, Abu-Saad Huijer Huda, Dracup Kathleen and Halfens Ruud. Self-care Behaviour of Patients with Heart Failure. Scand J caring science. Jun 2000; (14): 112-119.

8. O" Connel Macabasco Aurelia, Dewalt Darren A, Kimberly A. Brouucksou, W Baker David, Schillinger Dean, Ruo Bernice, Homes M George, Weinberger Morris. Relatioship between litracy, knowledge, self care behavior and health related quality of life among patient with heart failure. J Gen Intern Med. Sept. 2011; 26(9): 979-86.

9. Seto, Emily, Leonard, J Kelvin, Cafazzo, A Joseph, MA Caterina, Jan, Ross, J Heather. Self care and quality of life of heart failure patients at a Multidisciplinary heart function clinic. October 2011; 26(5): 377-385.

10. Dunn KS, Britz A Jody. Self care and quality of life among congestive heart failure patients. March 2010; 22: 48087.

11. $\mathrm{HH}$ Tung, SC Chen, WH Yin, $\mathrm{CH}$ Cheng, TJ Wang, SF Wu. Self-care behavior in patient with heart failure. Eur. Journal of cardiovascular nursing 2011; 34(1): 1-8.

12. S Heo Seongkum, Lennie Terry A, Okoli Chizimuzo, K Debra Moser. Quality of life in patients with heart failure. Heart lung.2009; 38(2): 100108.

13. Buck, H. G., Harkness, K., Wion, R., Carroll, S. L., Cosman, T., Kaasalainen, S., et al. (2015). Caregivers' contributions to heart failure self-care: a systematic review. European Journal of Cardiovascular Nursing: Journal of the Working Group on Cardiovascular Nursing of the European Society of Cardiology, 14 (1), 79-89. 
Anurag Bhai Patidar et.al. Self care of heart failure and health related quality of life among congestive heart failure patients in Punjab, India.

14. NN Huygen, P Jullamate and Kangchai Waree. Factor related to self-care behavior among older adults with heart failure. Special issues of the international journal of the computer, the internet and management $2011 ; 19$ : 71-6.
How to cite this article: Patidar AB, Kaur H, Kumar R. Self care of heart failure and health related quality of life among congestive heart failure patients in Punjab, India. Int J Health Sci Res. 2021; 11(4): 68-74. DOI: https://doi.org/10.52403/ ijhsr.20210409 